East African Medical Journal Vol. 83 No. 11 November 2006

CORNEAL DIAMETERS IN INFANTS BORN IN TWO HOSPITALS IN IBADAN, NIGERIA

A.O. Ashaye, FWACS, MSc, Departments of Ophthalmology, J.A. Olowu, FWACP, FMC Paed, Department of Paediatrics, College of Medicine, University of Ibadan, Ibadan, Nigeria and C.O. Adeoti, FWACS, FMCOphth. College of Health Sciences, Ladoke Akintola College of Technology, Osogbo, Nigeria

Request for reprints to: Dr. A.O. Ashaye, Department of Ophthalmology, College of Medicine, University of Ibadan, Ibadan, Nigeria

\title{
CORNEAL DIAMETERS IN INFANTS BORN IN TWO HOSPITALS IN IBADAN, NIGERIA
}

\author{
A.O. ASHAYE, J.A. OLOWU and C.O. ADEOTI
}

\begin{abstract}
Objectives: To measure the horizontal corneal diameters in infants at birth and compare with values reported in other studies.

Design: A cross-sectional hospital based study.

Subjects: All the healthy infants born within the period of one month in these hospitals were eligible for enrolment into the study. Horizontal corneal diameter measurements were performed with indirect caliper in both eyes of each of the 342 healthy full term infants and 25 preterm healthy infants born in these two hospitals. These results were evaluated according to the age of the infants Results: The corneal diameter in term infants was found to range from $9.00 \mathrm{~mm}$ to $12.50 \mathrm{~mm}$ during the first week of life with a mean of $10.26 \mathrm{~mm}(S D \pm 0.59 \mathrm{~mm}, \mathrm{n}=64)$. This is higher than what was reported for Caucasian infants $(P<0.01)$. Mean horizontal corneal diameter in all male infants aged 1-238 days was $11.06 \mathrm{~mm}$ (SD $0.75 \mathrm{~mm}, \mathrm{n}=187$ ), slightly higher than $10.93 \mathrm{~mm}$ (SD $0.22 \mathrm{~mm}$, $\mathbf{n}=154$ ) in all females, though this difference was not statistically significant. Horizontal corneal diameter increased progressively with age, from a mean value (SD) of $10.26 \mathrm{~mm}(0.72)$ to a mean value (SD) of $12.0 \mathrm{~mm}$ at 34 weeks of age. There was no significant difference in the mean corneal diameter of the right and left cornea. A few infants had corneal diameters of $12.50 \mathrm{~mm}$ and had no congenital glaucoma. Mean corneal diameter in preterm infants less than 37 weeks of gestation was $8.90 \mathrm{~mm}$ at birth (SD $1.25 \mathrm{~mm}, \mathrm{n}=25)$.

Conclusion: The horizontal diameter increased with age from birth to the 34 weeks of age. Changes after this period were not studied. The values obtained in these African infants were slightly higher than those reported from other populations.
\end{abstract}

\section{INTRODUCTION}

Corneal diameter measurements are done in the evaluation of children born with corneal anomalies and in particular the diagnosis and management of congenital glaucoma. In congenital glaucoma, deviations from normal in corneal diameters, in additional to other specific ocular features are diagnostic of the disease. The standard corneal diameters in infants at birth and its relation to gestational age remain unknown among African children. The standard measurements known and used for African children are those obtained in Caucasians. However, general and ocular biometric measurements suggest that there are racial variations, for example in birth weights, infant length, ocular axial length, corneal curvatures in children and adults and regional variations in the incidence of congenital glaucoma exists (1-4). There is therefore a need to obtain these measurements in African infants and children. 
Owing to the potential diagnostic importance of corneal diameter measurement, the present study was undertaken as a preliminary study to a larger one, which aims at finding normal values of corneal diameter in Nigerian infants, and comparing results with known values.

\section{MATERIALS AND METHODS}

This was a cross-sectional study carried out at two high volume maternity hospitals within Ibadan. Measurements of corneal diameters in infants born at Adeoyo State Hospital and Oluyoro Catholic Hospital Ibadan between March $5^{\text {th }} 1993$ and April $4^{\text {th }} 1993$ were carried out. These hospitals give secondary level care to patients and they refer highrisk pregnancies or babies to the tertiary centers. Users of these hospitals are from the low and middle level income groups and are about $72 \%$ Yorubas. The rest are from the other tribes in Nigeria, predominantly Ibos and Hausas. A large proportion of deliveries (approximately 55\%) in the city of Ibadan takes place in these hospitals.

All the healthy babies delivered with no abnormalities within the specified period formed the study population and were examined. Babies who were not examined before discharge from the wards were traced to the postnatal clinic where they were examined and corneal measurements were taken. Exclusion criteria included neonates born to mother with antenatal problems known to cause intrauterine growth retardation, stillbirths, multiple pregnancies and neonates with major congenital malformation. As a routine, birth-weight were measured within an hour of birth by trained staff, using standard scales which were corrected daily for zero error. The gestational age of the baby was based on the last menstrual period obtained from antenatal records. For the purpose of descriptive analysis, their ages were grouped into the following categories 1-7 days, 8-14 days, 15-30 days, 31-90 days, 91-180 days, 181-238 days. The duration of labour and mode of delivery were noted. The baby data recorded included the birth-weight in kilogramme and the sex of the infant.

A general examination was carried out by one of the authors OJA, a paediatrician, to exclude babies with any congenital malformations from the study and to note any ocular trauma. Thereafter, the horizontal corneal diameter measurements and weights of the babies were taken after the general examination. Therefore, all eligible infants had their measurements taken at the maternity wards or the postnatal clinic.

The horizontal corneal diameters were measured by one of the authors AOA, an Ophthalmologist using an indirect caliper. The horizontal corneal diameters were measured from white to white ensuring the instrument does not touch the globe. The reading was taken from the head end and behind the infant. The observer made three readings of each eye. The mean of the readings gave the corneal diameter for each eye. The presence of other obvious anomalies of corneal, pupil, anterior chamber and systemic abnormalities were noted. Ethical clearance was obtained from the hospital Ethical Review Board. Informed consents were obtained from the parents.

The data were entered onto a standardized form, checked for errors and entered into a personal computer. Statistical analysis involved calculation of mean and standard deviations. Mean corneal diameters were correlated with sex and age. The level of significance was set at p-value of 0.05 .

\section{RESULTS}

From March $5^{\text {th }} 1993$ to April $4^{\text {th }} 1993$, a total of four hundred and fifty nine live births were delivered at the Adeoyo Hospital and Oluyoro Catholic Hospital in Ibadan. Of these, twenty six (5.7\%) were excluded from the study because of maternal and neonatal conditions such as multiple pregnancy, eclampsia, anaemia and neonatal asphyxia. Therefore, four hundred and thirty three infants formed the study population. Out of these, three hundred and sixty eight infants were examined representing $85.0 \%$ of eligible babies participating in the study. The rest were discharged within 24 hours of delivery and did not turn up for postnatal clinic despite attempt by social workers to trace them and invite them to the postnatal clinic.

Out of those available for examination, 25 (6.8\%) were preterm infants delivered between 28 weeks to less than 37 weeks of gestation and $343(93.2 \%)$ were full term infants. Thus a total of 368 infants made up of three hundred and forty three full term and 25 preterm infants were examined.

All were healthy at the time of examination except a female full term infant who had hazy cornea 
in one eye and was therefore excluded from the study. The infant excluded did not have congenital glaucoma. Of the remaining 342 full term infants, $155(45.3 \%)$ were females, while 187 (54.7\%) were males. Their ages at the time of examination ranged from one day to 238 days (mean $=63$ days $\pm \mathrm{SD}$ ). The mean birth-weight was $3.04 \mathrm{~kg} \pm 0.54 \mathrm{~kg}$ ( $\mathrm{n}=$ 342). Males had a higher mean birth-weight of 3.10 $\mathrm{kg} \pm 0.59 \mathrm{~kg}$ compared to $2.96 \mathrm{~kg} \pm 0.41 \mathrm{~kg}$ in females.

Table 1 shows increase in horizontal corneal diameter with increasing age in the right and left cornea. The mean corneal diameter in the right eyes ranged from $10.26 \mathrm{~mm}$ among infants in the first week of life to $12.0 \mathrm{~mm}$ among those aged 181-240 days. This increasing trend was statistically significant $(\mathrm{p}<0.01)$.

There was no statistically significant difference between corneal diameter measurements of male and female infants, nor was there any difference in mean values of the right and left eyes.

Mean corneal diameter in full term males was $11.06 \pm \mathrm{SD} 0.75 \mathrm{~mm}(\mathrm{n}=187)$ range $9.00 \mathrm{~mm}$ to 12.50 $\mathrm{mm}$ ). Mean corneal diameter in full term female infants was $10.93 \mathrm{~mm} \pm \mathrm{SD} 0.72 \mathrm{~mm},(\mathrm{n}=155)$. Range was from $9.50 \mathrm{~mm}$ to $12.50 \mathrm{~mm}$ (Table 2). The mean corneal diameter of preterm infants ranged from 8.90 $\mathrm{mm}$ to $10.97 \mathrm{~mm}$. The mean corneal diameter of these preterm infants was less than the mean corneal diameter in full term infants, increased in boys and girls with age and was slightly higher in males than females preterm infants, although the difference was not statistically significant (Table 3).

Figure 1 shows the relationship between mean corneal diameter by age and sex in the study population.

Table 1

Corneal diameters in full term infants

\begin{tabular}{lccccccc}
\hline & \multicolumn{7}{c}{ Age in Days } \\
\hline Corneal Diameter & $1-7$ & $8-14$ & $15-30$ & $31-90$ & $91-180$ & $181-238$ & \\
& $\mathrm{n}=64$ & $\mathrm{n}=11$ & $\mathrm{n}=32$ & $\mathrm{n}=176$ & $\mathrm{n}=54$ & $\mathrm{n}=5$ & \\
\hline Right corneal diameter & & & & & & & \\
$\quad$ Mean (mm) & 10.26 & 10.23 & 10.72 & 11.22 & 11.32 & 12.0 & \\
SD (mm) & \pm 0.59 & \pm 0.72 & \pm 0.52 & \pm 0.64 & \pm 0.56 & \pm 0.00 & $\mathrm{P}<0.01$ \\
Range & $9.0-$ & $9.5-$ & $9.5-$ & $9.5-$ & $10.0-$ & $12.0-$ & \\
& 12.5 & 12.0 & 12.0 & 12.5 & 12.5 & 12.0 & \\
Left corneal diameter & & & & & & & \\
Mean (mm) & 10.27 & 10.23 & 10.72 & 11.21 & 11.32 & 12.0 & \\
SD (mm) & \pm 0.59 & \pm 0.72 & \pm 0.52 & \pm 0.63 & \pm 0.56 & \pm 0.00 & $\mathrm{P}<0.01$ \\
Range & $9.0-$ & $9.5-$ & $9.5-$ & $9.5-$ & $10.0-$ & $12.0-$ & \\
& 12.5 & 12.0 & 12.0 & 12.5 & 12.5 & 12.0 & \\
\hline
\end{tabular}

Table 2

Summary statistics of the corneal diameter in full term infants for right and left eyes by sex

\begin{tabular}{cccc}
\hline Measurement(mm) & Male & Female & P-value \\
\hline Right corneal diameter & & & \\
Mean(mm) & 11.06 & 10.93 & \\
SD & \pm 0.75 & \pm 0.72 & 0.09 \\
No. & 187 & 155 & \\
Range & $9.0-12.5$ & $9.5-12.5$ & \\
Left corneal diameter & & & \\
Mean (mm) & 11.06 & 10.91 & 0.064 \\
SD & \pm 0.59 & \pm 0.72 & \\
No. & 187 & 155 & \\
Range & $9.0-12.5$ & $9.5-12.5$ & \\
\hline
\end{tabular}


Table 3

Corneal diameter in 25 preterm infants by sex

\begin{tabular}{cccc}
\hline Measurement $(\mathrm{mm})$ & Male & Female & Total \\
\hline Right corneal diameter & & & \\
Mean $(\mathrm{mm})$ & 9.32 & 8.48 & $8.90 \pm 1.75$ \\
SD & \pm 1.62 & \pm 0.95 & \\
No. & 14 & 11 & \\
Range & $8.90-10.97$ & & \\
\hline
\end{tabular}

Table 4

Birthweight by sex of 342 full term infants and 25 preterm infants

\begin{tabular}{lcccccr}
\hline Measurement $(\mathrm{mm})$ & \multicolumn{2}{c}{ Male } & \multicolumn{2}{c}{ Female } & \multicolumn{2}{c}{ Total } \\
\hline & Mean & SD & Mean & SD & Mean & SD \\
Full term & 3.15 & 0.59 & 3.06 & 0.41 & 3.04 & 0.54 \\
No. & \multicolumn{2}{c}{187} & \multicolumn{2}{c}{155} & \multicolumn{2}{c}{342} \\
Pre-term & 3.01 & 0.60 & 2.82 & 0.47 & 2.91 & 0.57 \\
\hline
\end{tabular}

Figure 1

Mean corneal diameters for Nigerian infants by age and sex

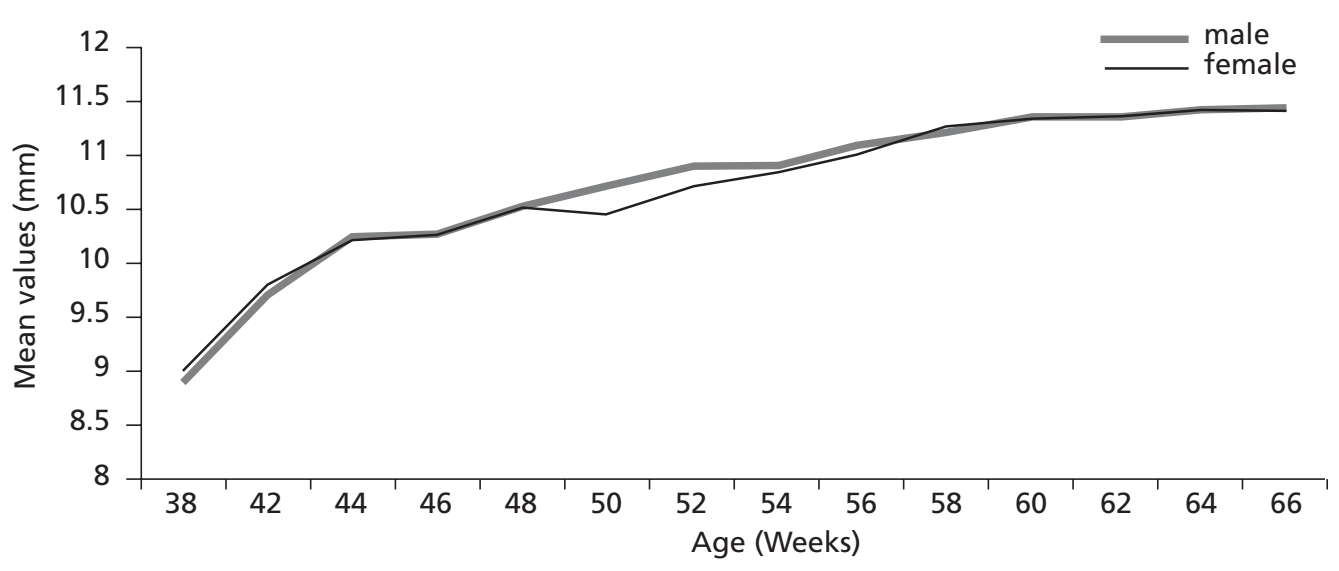

DISCUSSION

It is important to establish local standard values for corneal diameters values, which can be useful in diagnosis and management of corneal problems in infancy in developing countries. It is well known that anthropometric values like birth-weight, infant length, and ocular biometric measurements such as corneal curvatures, axial length are influenced by racial and environmental factors (2-4,7-9). The changes in these measurements with growth also varies. The ocular biometric values at birth and subsequent changes in African infants are yet unknown.
Corneal curvatures, axial lengths are important variables that determine growth of infant's eye. Although more information could be obtained from corneal curvatures and axial length, these measurements need equipments and expertise of their use in children. Corneal diameter measurements require simpler tools and this preliminary study generated values for a few preterm infants and more full-term infants born within a defined period in two African hospitals which should be useful in evaluating infants with corneal problems. However, the small number of infants studied limits generalisation of the values obtained, but the experience should help in planning a larger study. 
The results of the study showed the increase in corneal size with increasing age, with a mean value of $10.26 \mathrm{~mm}$ in the first week of life to a mean value of $12.0 \mathrm{~mm}$ a 34 weeks of age. Slight differences exist between males and females; males have slightly higher values than females. These differences however were not statistically significant. The increase in corneal diameter with age had been similarly found in other population $(11,12)$ but a slight difference was found between the mean cornea diameter of African infants and those reported in the literature $(11,12)$.

Three reasons can be adduced for the slightly higher value obtained in the children studied here. It could be due to differences in study methodology such as the measurement techniques, sample size and maternal/baby characteristics.

The first is the methodology of measurements, there being four readily available methods for measuring corneal diameter as follows (a) placing a ruler near the eye or nose, (b) indirect caliper reading from cornea, (c) using slit lamp attachment and (d) photographic measurements. The latter two methods are non-invasive and permanent records are kept but the costs could be too high in a developing country. Besides, it has been documented that the photographic measurements correlate well with standard caliper measurement (5). The indirect caliper measurements are often used in infants after topical anaesthetic instillation or sometimes general anaesthesia. While this may be necessary if the caliper was made to touch the globe, the use of anaesthetic was found unnecessary in this study because the globe was not touched during measurements. Vertical corneal diameters would have been more technically difficult without a topical anaesthetic agent though, horizontal corneal diameter was measured in this study. Millimeter ruler measurements are not considered as accurate but are safe but the caliper measurement, carefully used by an ophthalmologist is also safe (5). No problems were encountered while using this method in the present study. Inter-observer error was minimised because one investigator took the three measurements, and the readings averaged.

Secondly, the differences could also be due to the small sample size. The infants studied herein may not be representative of the whole population of newborns, though they do have similar characteristics with those previously reported in
Nigeria in terms of birth-weights and other maternal characteristics $(3,4,6,8)$ hence corneal data of this study population should be close to that on Nigerian newborns.

The mean birth-weight for full term infants was observed to be $3.04 \pm 0.54 \mathrm{~kg}$. Males had a higher mean birth weight of $3.10 \pm 0.59 \mathrm{~kg}$ compared with $2.96 \pm 0.41 \mathrm{~kg}$ for females $(\mathrm{p}<0.01)$. However these values (Table 4) although similar to the mean birth weights reported in Nigeria $(3,4,6)$ is lower than that for Caucasian newborns (13). These differences in birth weight distributions are known to be due to a difference in the socioeconomic status and anthropometric parameters in the communities studied.

The method of ascertaining gestational age by history and physical examination may however lead to erroneous calculations of gestational age since majority of mothers do not know for sure their last menstrual period. As expected mean birth weight in preterm infants was much lower than in full term infants.

The maternal and birth-weight characteristics in the infants studied here differ from those of Caucasians (9). This may partly explain the differences in corneal diameter in the infants studied here and the reported values.

The average horizontal corneal diameter reported in literature is $9.5 \mathrm{~mm}$ to $10.5 \mathrm{~mm}$ in the newborns $(11,12)$. By one year of age normal corneal diameter is expected to vary from $10.0 \mathrm{~mm}$ to $11.5 \mathrm{~mm}$ (12). The cornea grows slowly to reach an adult size of $12 \mathrm{~mm}$ by two years of age. It has been suggested that children with corneal diameter larger than $12.0 \mathrm{~mm}$ should be suspected to have glaucoma (12). In this series, a few of the infants had horizontal corneal diameter value of $12.50 \mathrm{~mm}$ but did not have congenital glaucoma at the time of examination. It could not be established that they did not develop glaucoma later on in life as there was no follow-up. Follow-up and serial measurements in this series of babies could have provided such information. These measurements shall be included in the future studies.

The slight differences in corneal diameter with sex could be due to the differences in weight found in the two groups. Male infants weighed more than female infants.

Differences in birth-weight are modified by known variables such as maternal age, haemoglobin concentration and parity among others. These factors 
could contribute to the differences between the results obtained in this study and others. Africans have higher rates of low birth-weights and preterm delivery than Caucasians and in this study, the corneal diameter measurement does differ slightly from values reported. Whether such differences are related to birth parameters, genetic or environmental factors still need to be further studied.

In conclusion, the mean horizontal corneal diameters of infants studied in this series are slightly larger than reported corneal diameters $(\mathrm{P}<0.01)$. The corneal diameters in preterm infants are smaller than in full term infants. In these Nigerian infants as in infants of other population, corneal diameter increases with age from birth. This preliminary study, gives some information on the corneal diameter in Nigerian African infants. Although the study population is not large, the results are interesting enough to undertake a larger population study.

\section{REFERENCES}

1. Friling R., Weinberger O., Kremer I., Avisar R. et al. Keratometry measurements in preterm and full term newborn infants. Brit. J. Ophthalmol. 2004; 88: 8-10.

2. Patwavi A.K., Kulmarni R., Aneja S. and Audu I. Anthropometric standards of priviledged neonates in Maiduguri, Nigeria. Cent. Afr. J. Med. 1988; 34: 78-84.

3. Ladipo O.A. and Adeluis B. Birthweights of Nigerian children at Ibadan. East Afr. Med. J. 1977; 54: 31-37.

4. Effiong C.E., Laditan A.A.O., Aimakhu V.F. and
Ayeni O. Birthweight of Nigerian children. Nigeria Med. J. 1976; 6: 63-68.

5. Robinson J., Gilmore K.J. and Fielder A. Validation of a photographic method of measuring corneal diameter. Brit. J. Ophthalmol. 1989; 73: 570-573.

6. Adelusi B. and Ladipo O.A. Preterm and other babies with low birth weights in Ibadan. Trop. Georg. Med. 1976; 28: 316-322.

7. Kirchengast S. and Hartmann B. Impact of maternal age and maternal somatic characteristics on newborn size. Amer. J. Human Biol. 2003; 15: 220-228.

8. Onadeko M.O., Avokey F. and Lawoyin T.O. Observations of stillbirths, birth weight and maternal haemoglobin in teenage pregnancy in Ibadan, Nigeria. Afr. J. Med. E Med. Scin. 1996; 25: 81-86.

9. Steer P.J., Alam M.A., Wadsworth J. and Welch A. Relationship between maternal haemoglobin concentration and birth weight in different ethnic groups. Brit. Med. J. 1995; 310: 489-491.

10. Fedeis H.C. Preterm delivery and subsequent ocular development. A 7-10 year follow-up of children screened 1982-84 for retinopathy of prematurity 4 . Oculometric and other metric consideration. Acta. Ophthalmol. Scan. 1996; 74: 301-305.

11. Duke-EIder S. The anatomy of the visual system in system of ophthalmology. London, Henry Kimpton, 1961; 94-98.

12. Isenberg S.J. The eye in infancy. Chicago: Year book Medical Publishers. 1989.

13. Johnston P.E. and Beller A. Anthropometric evaluation of the body composition of black, white and Puerto Rican newborns. Amer. J. Clin. Nutr. 1976; 26: 61-65. 